\title{
VIEWER TAGGING IN ART MUSEUMS: COMPARISONS TO CONCEPTS AND VOCABULARIES OF ART MUSEUM VISITORS
}

\author{
Martha Kellogg Smith <mkelsmit@u.washington.edu> \\ The Information School \\ University of Washington \\ Box 352840 \\ Mary Gates Hall, Ste 370 \\ Seattle, WA 98195-2840, USA
}

\begin{abstract}
As one important experiment in the social or user-generated classification of online cultural heritage resources collections, art museums are leading the effort to elicit keyword descriptions of artwork images from online museum visitors. The motivations for having online viewerspresumably largely non-art-specialists - describe art images are (a) to generate keywords for image and object records in museum information retrieval systems in a cost-effective way and (b) to engage online visitors with the artworks and with each other by inviting visitors to express themselves and share their descriptions of artworks. This paper explores the question of how effective non-specialist art keyworders can be in capturing ("tagging") potentially useful concepts and terms for use in art information retrieval systems. To do this, the paper compares evidence from art museum visitor studies which describe how non-specialist art viewers react to and describe artworks and use museum-supplied information in their initial encounters with artworks. A theoretical model of artwork interpretation derived from art museum visitor research provides a framework with which to examine both the activity and the products of artwork tagging for image and information retrieval.
\end{abstract}

\section{Introduction}

As one important experiment in the social or user-generated classification of online cultural heritage resources collections, art museums are leading the effort to elicit keyword descriptions of artwork images from online museum visitors. These experiments are part of art museums' Webbased outreach to an increasing diversity of museum visitors and information seekers. Current 
prototype keyword collection interfaces are being tested by, among others, The Metropolitan Museum of Art, the Guggenheim Museum, and the Cleveland Museum of Art.

The motivations for having online viewers — presumably largely non-art-specialists—describe art images are (a) to generate keywords for image and object records in museum information retrieval systems in a cost-effective way and (b) to engage online visitors with the artworks and with each other by inviting visitors to express themselves and share their descriptions of artworks. Art museums focus on eliciting terms for "subjects" in artworks, that is, pictured people, objects, events and actions, locations, and simple moods or emotions, since these are not normally captured in traditional artwork description in museum object records. The assumption is that pictorial and emotional subject description, particularly phrased in non-specialist terminology, is especially useful and appealing for generalist system users to access artwork images and information. An example from the Cleveland Museum of Art's term collection interface suggest terms like man, portrait, formal, American, and wig for an $18^{\text {th }}$-century portrait of a gentleman (from Bearman and Trant, 2005, fig. 1).

This paper explores the question of how effective non-specialist art keyworders can be in capturing ("tagging") potentially useful concepts and terms for use in art information retrieval systems. To do this, the paper compares evidence from art museum visitor studies which describe how non-specialist art viewers react to and describe artworks and use museum-supplied information in their initial engagement with artworks. This research provides a framework with which to examine both the activity and the products of artwork tagging for image and information retrieval.

\section{Background: Art Museum Documentation for Non-Specialist Information Access}

Stimulated by new Web technologies and the promised access to rich art object information, images, and thematic exhibitions, non-specialist art audiences are challenging art museums to create new avenues of access and new ways of presenting art concepts and vocabularies.

Museums serve $21^{\text {st }}$-century visitors and learners of great variety in ages, economic means, ethnic and racial backgrounds, multilingual abilities, learning styles, and world views (Institute for Museum and Library Services, 1999). As museum system audiences change from primarily specialist users (curatorial and academic) to a more diverse mix of audiences, and as attendees to 
art museums now include online as well as in-house visitors, designing new approaches to accessing museum content to appeal to and be meaningful to this variety of learners is essential. (In recognition of the growing role of art museum websites to attract large audiences, the term "museum visitor" will be used in this paper to encompass both online and in-house visitors. The term "non-specialist" will be used here to indicate general art museum visitors who are engaged in leisure learning rather than research or study tasks for academic work or school assignments.)

\subsection{Subject indexing in art museum documentation}

General art museum visitors' expectations of extensive descriptive and interpretive artwork information are not often matched by the current reality of art museum systems' documentation content, however. What has been called "label copy" forms the core descriptive formula of factual identification information about art objects in museum information systems. It provides creator, title, date, medium, measurements, credit lines, and object number within the museum (Seren, Donohue, and Underwood, 2001, p. 31). However, label copy does not contain subject or thematic descriptions or contextual material for the objects (other than that embedded in some artwork titles). Only a handful of art museums worldwide offer extensive artwork "subject" searching specifically, that is, keyword access through a website browser or in-house system to persons, events, locations, and objects depicted in individual artworks or to abstract themes, narratives, styles, or historic contexts that are either unique to single artworks or tie together sets of artworks. However, these search systems often rely more on free-text keyword searching of image captions than on fielded subject vocabularies, thus, retrieval consistency is a problem.

The practice of art object and image subject indexing in art museums is still very limited, partly because of the limited guidelines on analyzing and describing subjects of artworks for retrieval systems (White, 2002). Also, curatorial opinions sometimes vary on what descriptive terms to use to capture subject themes (Gilchrest, 2003, pp. 14-15). More than anything, the lack of extensive subject indexing is hampered by a lack of knowledge about how useful this is to end users. We do have some evidence that art viewers want subject access to artworks in publicly available print and digital image collections (Frost, Taylor, Noakes, Markel, Torres, and Drabenstott, 2000; Gordon, 1996; Hourihane, 1996). However, we have little information on the specific types of subjects requested by non-art-specialist searchers in particular. The assumption is that general art museum information system users would desire such access. 


\subsection{Specialized art vocabularies}

A number of writers on cultural heritage information point out that art and museum terminology for both subject and object description may baffle non-specialists and hinder information seeking in museum texts and information systems (see, e.g., Dunn, 2000, section 4; Janney and Sledge, 1995, section 5; and Zorich, 1997, pp. 186-188). Non-specialists may not use terms in comments or questions that match what experts use. As Gilliland-Swetland and White put it, "descriptions of museum objects... may be written for curators and scholars, and the words preferred by experts might not jibe with words used and understood by others seeking information and images" (Gilliland-Swetland and White, 2004, p. 26).

\subsection{Testbed collections and user studies}

Lastly, there is a lack of test collections for research on users, because so few art museum or other online art image and information systems are cataloged and indexed fully. Art object description practices and knowledge organization tools simply have not been tested among general museum audiences seeking art information. The lack of subject indexing, in particular, thwarts the opportunities to explore the apparent appetite that non-specialist audiences have for subject access to art objects and images and to test whether tools such as subject vocabularies and classification schemas can capture what non-specialists would like to know about artwork subjects.

Projects for viewer tagging in art museums seek to address all of these issues: to populate art object records with viewer-generated terms for searching, to research how non-specialists describe artworks in their own words - particularly for artwork "subjects" broadly defined — and to gauge the usefulness of tagging for general audience retrieval use.

\section{Art Museum Tagging Research Projects}

Viewer tagging in the art museum context is defined as a process "where 'tags' (user-supplied access points for works of art, or other information resources) are supplied by the general public (museums' audience) in a common on-line environment and shared between them." The resulting "socially constructed classification" system is a folksonomy (definitions from Trant, 2006, p. 85). Part of an experimental trend toward the "democratic indexing" of images (Brown, 
Hidderley, Griffin, and Rollason, 1996), collaborative tagging of art images is phenomenon made possible and plausible by new technologies and also by new socio-technical communities, including participants in chats and listservs, through which museums respond to the participatory and social needs of museum visitors.

\subsection{Motivations for artwork tagging: Conceptual access and vocabularies}

Museum researchers see viewer tagging as creating new types of access to art images and information, because it generates search concepts and vocabularies from a non-specialist point of view. In describing the limits of current museum documentation, Trant and Wyman state that "neither the authored [museum exhibition mode] nor the database model [museum object records] of collections information fully supports museums' goals to enable use and understanding of the objects in their care. Collections are available, but not necessarily accessible" (Trant and Wyman, 2006, p. 1).

Tagging is seen as one method of allowing non-specialists to overcome what Chun calls the "specialist discourse" and the use of specialized "idioms of art historical documentation" in the description practices of museum curators and registrars (Chun, Cherry, Hiwiller, Trant, and Wyman, 2006, section A1). Bearman and Trant argue that a "vernacular view of objects"implying access to more easily grasped concepts in a more everyday vocabulary - is needed for non-specialist access to object records (Bearman and Trant, 2005, Objectives section). This vocabulary argument is related to the primary searching and access argument: that there is a “semantic gap" between specialists' artwork descriptions in standard museum records and what non-specialists are familiar with that shuts out many information and image seekers. Invitations to volunteers to participate in tagging often cast the task as helping other general viewers by imagining what terms they themselves would use to search for an artwork in a database collection. For example, the Metropolitan Museum's invitation urges taggers to apply "terms you would use if you were trying to find this image" (quoted in Trant and Wyman, 2006, p. 2).

\subsection{Early results of current tagging projects}

The primary objectives for current tagging projects in art museums are to create Web tagging interface prototypes, to develop research questions and agendas, and to test description and retrieval effectiveness with growing databases of viewer-tagged art object records. The most 
detailed results of these projects to have been analyzed and made available are those from tagging experiments conducted in 2004-2005 with library staff, administrative staff, and volunteers at The Metropolitan Museum of Art, New York. This series of experiments gathered terms from a total of 49 taggers for 45 different art objects. The tests gathered responses both on paper and in three types of online presentation interfaces (with and without basic descriptive "tombstone" information, and prompting for selected categories of terms; see Trant, 2006, pp. 87-101).

Early results of these keywording experiments indicate that non-curatorial art viewers provideas they are encouraged to do-descriptions of obviously visible pictorial elements (e.g., nudes, girl in chair, meadow, calligraphy) and commonly recognized visual and abstract concepts (e.g., aerial topography, symbolism, classical mythology, poverty). A smaller number of keywords capture more complex or art-specific ideas (e.g., fête champêtre) and moods (e.g., melancholy, peaceful wilderness) (The Metropolitan Museum of Art, 2005; see also Trant and Wyman, 2006, p. 2). Thus, volunteer taggers do provide many terms that are not in standard art object records in museum collection management systems. Eighty-eight percent of tagger terms were not already in the Metropolitan Museum's object description system. Three-quarters of these terms were judged valid and "appropriate" to these artworks by museum's Subject Cataloguing Committee (Trant, 2006, p. 97).

\section{Empirical Evidence and Theoretical Constructs From Art Museum Visitor Studies Relevant to Artwork Tagging}

To expand perspectives on these tagging projects in art museums, evidence from existing research on art museum visitors can provide relevant information on the concepts and vocabularies desired and used by non-specialist art viewers and on how viewers express themselves. The evidence presented here is culled from a meta-analysis of art museum visitor studies which examines what general adult audiences are interested in, how they browse in the galleries among artwork originals and their text information, and their uses and preferences for art information (Smith, 2006). The research analyzes the results of qualitative visitor studies conducted at 23 North American art museums and reported in 12 separate studies (including collections of sub-studies) involving several thousand museum visitor participants. This research focuses on in-house art museum visitors but has applicability to online visitors as well, because the content and organization of museum information systems are increasingly being designed to serve both physical and virtual museum sites. 
In the following sections, we will look first at the empirical evidence and the resulting models of art museum visitor artwork interpretation and information use found in these studies, then relate them to the theory of iconographic interpretation of artwork subjects which underlies current existing library and information science (LIS) image interpretation research and subject indexing guidelines.

Evidence summarized in the next section was gathered from the art museum visitor studies of Abu-Shumays and Leinhard (2002), Duhaime, Joy, and Ross (1989), Eversmann, Krill, TwissGarrity, and Beck (1997), The Getty Center for Education in the Arts and The J. Paul Getty Museum (1991), Housen (1987), Leinhardt, Tittle, and Knutson (2002), Mann (1993), McDermott-Lewis (1990), Lockett (1991), Smithsonian Institution, Office of Policy and Analysis (2004, 2005), Stainton (2002), and Worts (1995). The reader is referred to Smith (2006) for exact citations from these sources.

\subsection{Levels of artwork interpretation and information use}

Art museum visitor studies provide a picture of the visual observation and verbal description skills of non-specialist art viewers that have relevance to the skills and terminology choices of non-specialist taggers in describing artworks. The tendency of non-specialist art viewers to verbalize about and list out familiar and recognizable elements when first exploring artworks in order to understand them has been identified empirically in these studies and has also been identified in art education studies of aesthetic development (see, e.g., Housen, 1983). This indicates general empirical support for engaging taggers in what comes naturally to non-specialist viewers in the early stage of encountering artworks, particularly verbalizing about artworks based on initial reactions which draw on what is seen concretely in the works and on personal memories, associations, and emotions.

Art museum visitor studies describe inexperienced art viewers as beginning with a "reactive stance" which marks the start of the process of artwork interpretation. Their first impulse is to describe and list the elements of what they see. Starting with weak art-viewing skills and not knowing exactly what to look for, viewers zero in on obvious and concrete features of artworks, notably their subject matter of depicted objects, figures, events, and locations, those parts of the artworks that are most accessible based on everyday visual experience. Inexperienced viewers 
prefer realistic works, that is, with easily recognizable and describable forms, over more abstract works. Because viewers lack a large vocabulary of art terms and concepts and have an undeveloped sense of critical analysis, they have trouble discussing formal features such as compositions and qualities of space and light except in simple terms.

Because they lack a broader knowledge of art, inexperienced viewers rely first on their own emotions, memories, associations, and values in assessing works. They use "gut reactions" and often give artworks personal and idiosyncratic interpretations. They form of quick judgments about artworks, based on their personal reactions, for example, to the colors or how good or bad a work makes them feel, rather than based in critical analysis using supplied contextual information. They find it hard to explain their judgments very deeply, however, because they lack an analytical vocabulary and knowledge of the creative and cultural contexts of these artworks.

Theories of interpretation among novice art viewers developed by art educators also describe this early stage of encountering and describing artworks at a simple level. For example, in Housen's 5-stage model of aesthetic development, Stage I Accountative interpretation is primarily reactive. Viewers' artwork interpretations emerge from random observations of concrete aspects of the artwork and from personal experiences and associations. In Stage II Constructive interpretation, viewers try to build a framework for their understanding, actively comparing the artworks to what they know of the visual and functional world, hence their need for artwork realism to use in making these comparisons (Housen, 1983, 1987).

This first phase of artwork interpretation culminates with a growing awareness of other comparisons to be made beyond viewers' own personal experiences and the need to refer to contextual information provided by the museum. Viewers seek brief synopses of artworks (most often in object wall labels) that include information on depicted stories and characters, symbolism and abstract themes, media and techniques, and the original creation contexts and functions of these works. These museum texts present viewers with art historical vocabulary terms which are often new to them. Viewers towards the end of this initial stage then begin to seek definitions of art vocabulary which they admit they lack. They practice terms by using "text echo," the reading aloud of text passages among a group of visitors (first described by McManus, 1989; see also Stainton, p. 238) and by using terms learned on museum tours (Eversmann, p. 148). 
Thus, non-specialist artwork viewing and interpretation can be seen as a developmental progression of increasing art knowledge and interpretive skill. Three levels are identified from art museum visitor studies:

- Level I involves describing, listing, enumerating, and naming objects and their parts, but in a relatively unorganized and self-centered fashion, with a focus on concretely observed characteristics of the objects and the use of personal reactions and associations.

- Level II involves classifying and contextualizing artworks by comparing them to remembered (or nearby) art objects along dimensions such as styles, dates, and original and historical settings and functions. This level requires additional contextual information about artworks at hand and related artworks and increasing knowledge of art vocabulary.

- Level III involves evaluating, explaining, and synthesizing the many strands of visual, personal, comparative, and contextual information in order to create personally understandable and satisfying interpretations of artworks at a relatively high level of integrative skill.

The outcome of this three-step process of meaning-making is for viewers to relate artworks to their own lives and experiences and to place them in their larger understanding of art and human culture.

\subsection{Relations to the iconographic theory of art object and image indexing}

Types of Level I viewer responses reported in art museum visitor studies and their resulting models of information use correspond to the pre-iconographic level of artwork description in the theoretical approach to subject analysis and meaning-making proposed by art historian Erwin Panofsky (Panofsky, 1955). The logical adaptation of Panofsky's iconographic analytic approach by LIS theorists, first suggested by Markey $(1983,1986)$ and later refined by Shatford (Shatford, 1986), has formed the basis of now widely accepted principles of subject analysis for the indexing of art and cultural objects and images for museum documentation and LIS visual resources practice more generally. It is embedded in professional guidelines for subject analysis and 
description most notably in the Getty Standards and Digital Resource Management Program's Categories for the Description of Works of Art (CDWA).

Panofsky's Level I of meaning-making entails listing and describing primary or natural subject matter, that is, depicted "everyday" generic objects, events, people, and simple emotional states as a first step in decoding artworks (for example, nude man, battle, city). Panofsky's Level II icongraphic analysis requires further identifying these simple depictions as named or specific people, objects, or events, and linking them to conventional themes and stories in art (for example, Hercules, Battle of Anghiari, Nineveh). Finally, the iconological analysis at Level III describes the deeper meanings that these depictions, themes, and stories have in the contexts of particular artwork's creation and culture. The latter two levels require increasing art vocabulary familiarity and analytic expertise.

Thus the empirical evidence from art museum visitor studies supports the Panofskian model in general and tells us more about how inexperienced non-specialist art viewers begin to interpret and make sense from artworks. It is no surprise that non-specialist art image taggers generate terms primarily at Panofsky's Level I. However, this does not mean that non-specialists want to limit themselves to retrieving either images or art information at this level. The implications of this for art museum viewer tagging are discussed in the next section.

\section{Implications for Art Museum Tagging Motivations and Success}

\subsection{Searching utility of Level I terms}

It has been assumed by LIS image retrieval researchers and theorists that non-art-specialists must search for simpler depicted elements (cast in this research as Panofsky's Level I elements) because they will be, by definition, less familiar with Level II and III elements (Enser, 1995; Jorgensen, 2003; Markey, 1983; Shatford, 1986). There is, however, very little evidence in LIS image retrieval research that these generic elements are indeed what non-specialists search or browse for or that more common, everyday terms lead non-specialist searchers to what they want.

From the lists of terms collected in artwork tagging experiments, we know that volunteer artwork tagging supplies primarily Level I subject concepts and terms. But evidence from art museum visitor studies indicates that viewers in the presence of real artworks soon express a need for 
Level II contextual information. Evidence from both aesthetic development models and art museum visitor studies indicate that non-art-specialist viewers, at least in their efforts to learn about art in general, do want to move beyond simple descriptions into a deeper array of artwork information. Novice art viewers in museums rapidly request synopses of basic information about artworks including fuller explanations of subjects and themes, contextual information about artworks' historical and cultural origins, and explanations of the significance of the works. Of particular relevance here, by "subjects" viewers seem to mean the identification of named stories, characters, symbols, and the supply of contextual background information (Level II information), not the identification of things they can already see for themselves (Level I information).

Novice viewers do expect art museums, as the "authorized knowers" (Lisus and Ericson, 1999, pp. 201, 205) to provide contextual Level II information in accessible, non-technical ways, especially explained in accessible vocabularies. If viewers are searching for this type of information in an image or information retrieval system, the search is more complex that just querying for or perusing lists of depicted elements. Information-seeking even for non-artspecialists draws on all three levels of Panofsky's system of description and interpretation and those levels delineated in art museum visitor studies.

Tagging of Level I elements does have great utility, of course. These more concrete terms may come into play when searching for known artworks or specific_motifs and when tracing expressions of forms over a collection of artworks. Searchers of all levels of expertise may well want to retrieve artworks by Level I elements (indeed, this is typical for art historians searching on certain visual motifs at a pre-iconographic level). But searchers themselves must then make the connections to more complex meanings constructed from these Level I elements.

\subsection{Vocabularies}

Tagging of visual elements does not assuage the "vocabulary problem" of non-specialists in the end. Level I terms do not necessarily create meaningful bridges between visual elements and deeper meanings in artworks as expressed in symbolic or expressive combinations of depicted elements. Tagging does not help non-specialist viewers with art historical and foreign language terms (or national, ethnic, or tribal terminologies) that do need to be understood in order to help them to develop understandings of art with new contextual information at Levels II and III. 
There is some evidence that non-specialists do resent "artspeak," especially in curatorial discussions of contemporary art. Indeed, there seems to be an assumption about an "elitism" surrounding art terminology which is reflected in non-specialist museum visitor attitudes. But visitors overcome their fear of unfamiliar terminology by using techniques like text echo and reusing terms heard on tours. Frustration with art terms used in museum texts is more in response to a lack of explanations or definitions, the overuse of these terms, and inconsistencies in the use of these terms over different museum texts.

The point for museums in this effort must be to increase access to and understanding of art images and information not only by providing Level I descriptions, but also by increasing the accessibility to authoritative information expressed in specialized vocabularies. Specialist terms do capture concepts of art that - while they need clear definitions and explanations (preferably illustrated) - are part of learning about art. In sum, tagging as simply identifying generic visual content does not further broader understanding, except as a first step in getting viewers to really look at artworks carefully and begin a descriptive and further information-seeking process.

\subsection{Viewers as taggers: Implications for quality, consistency, and coverage of tags}

If taggers are keywording with primarily Level I terms as instructed, this raises some overall concerns about the depth and coverage of user-supplied descriptions, particularly when we consider where non-specialist viewers are on a developmental scale of art viewing and description skills. Inexperienced viewers are aware and state that they lack of art knowledge and vocabulary. Viewers will also supply common words because they lack experience in describing artworks. That there was a "surprising amount of consistency in the terms that were assigned to works in the groups Image Alone and Image with Caption" in the Metropolitan Museum experiments (Trant, 2006, p. 94) is probably not surprising. It reflects novice viewers naming commonly perceived aspects.

This lack of knowledge also suggests the possibility for imprecision, error, and uncertainty, not to mention variations in specificity and granularity, in their term selection for several reasons. As taggers they may choose "easier" works to tag since more approachable and understandable works are what inexperienced art museum visitors say they prefer to view when they visit. Inexperienced viewers prefer pictorial realism in artwork styles and find contemporary and abstract art more difficult to understand and comment on. An avoidance of tagging more 
difficult — particularly abstract—works may result in uneven keywording coverage of works in a collection. Even if taggers are "required" to tag given images they may provide thinner and possibly more general-level tags to works with unfamiliar styles or depicted elements from distant cultures or eras. This was evidenced in the Metropolitan Museum's experience of taggers who assigned fewer terms and a higher percentage of invalid terms to works such as a "nonrepresentational Arabic manuscript page" and a work of "unfamiliar African sculpture with challenging iconography" (Trant, 2006, pp. 94, 100).

Also not surprising is the taggers' tendency to provide fewer tags and more invalid tags when given the category prompts to group their tags (Trant, 2006, pp. 94, 99). This indicates that they are unsure about the definitions and scope of broader art concept categories, in addition to specific descriptive vocabularies. Bar-Ilan and colleagues found a related confusion among taggers who, for example, entered the same term Torah in both General Themes and Symbols categories in a project tagging a collection of Israeli and Jewish cultural heritage images (BarIlan, Shoham, Idan, Miller, and Shachak, 2006, section 3). This parallels the evident ambiguous interpretation of the notion of "subjects" as a broad category of information for art museum visitors who consider subjects to fall into a range of categories including pictured stories and abstract themes, symbols, and original functions of art objects.

\section{Conclusion}

Art museum visitor studies tell us about the concepts and vocabularies that non-art-specialist viewers use when they react to and begin to describe artworks in words. This evidence helps us to gauge the potential effectiveness of non-specialist concepts and vocabularies in tagging artworks. Artwork tagging as an viewer-engaging activity fits well with a developmental Level I knowledge base and information behaviors of describing, listing, enumerating, and naming objects. However, non-specialist viewer preferences (for example, for more realistic artworks) and their relatively undeveloped skills of verbalizing about art are likely to have an impact on the quality, consistency, and coverage of the keywording they provide.

Tagging has the potential of increasing access to artwork images and records dramatically for searchers of all levels of expertise. For non-art-specialists it will increase conceptual access to ideas on their initial level of understanding, and it will expand artwork descriptions in their terminology. Access to the ideas of their peers in the language of their peers (and reassurance 
that they are thinking along the same lines when they see similar terms in their own "vernacular") is important to non-specialist viewers - witness the marked preference for visiting art museums with others. But this is not the same thing as a simplified access to authoritative museum information, some of which is cast, inevitably, in new terminology to be learned. Subjects, themes, and concepts are embedded in art historical (and foreign language) terms that need to be defined and explained in terms non-specialists can understand.

Overcoming the semantic gap between art historical terminology used in current museum descriptions and what non-specialists can understand needs to be addressed in ways other than tagging. We know from art museum visitor studies at that non-specialist information seekers want more complex contextual information beyond the identification of visually obvious things. It is in this area that the following suggestion for new research on artwork tagging is made:

Tagging projects are very useful for the rich fund of verbal data from non-specialist art viewers they provide. How can art museum educators be involved in the analysis and use of these terms to increase non-specialist access to art concepts and terminology? Because of their familiarity with both novice art viewers and the artworks themselves (particularly in their own collections), art educators could suggest ways and vocabularies to build the needed bridges between Level I terms and Level II and III concepts. In what ways can simpler descriptions be used to lead in to more complex themes, stories, and specialized vocabularies?

For now, care needs to be taken by art museums to be clear - to themselves and to their visitorsabout their motives in inviting viewers to provide basic-level descriptions and keywording. One museum goal is to populate retrieval systems with access points and to serve searchers of all levels of expertise who are interested in finding depicted elements in artworks in simple terminology. However, we have much to learn about non-specialist art viewers and what they consider the most useful subject vocabularies and access points to art images and information and, indeed, about what non-specialists even consider to be "subjects" of artworks.

Another goal of art museum tagging is to encourage viewers to engage in detailed visual examination and verbal description of artworks, a necessary first step in learning about art. Teaching viewers how to look carefully at artworks and to express themselves about art serves art museums' central function as educational institutions. However, confusion of this pedagogical goal with the generation of keywords for populating systems should not inadvertently encourage 
non-specialist volunteer taggers to interpret their keywording activity as somehow what art viewing and meaning-making is all about: simply enumerating and listing what they see. Museums need to create ways of encouraging non-specialist viewer participation beyond eliciting this type of simple listing response by developing tools (for example, collaborative annotation systems) to elicit and support deeper levels of personal interpretation, learning, and discussion.

\section{References}

Abu-Shumays, M., and Leinhard, G. (2002). Two docents in three museums: Central and peripheral participation. In G. Leinhardt, K. Crowley, and K. Knutson (eds.), Learning conversations in museums (pp. 45-80). Mahwah, NJ: Lawrence Erlbaum.

Bar-Ilan, J., Shoham, S., Idan, A., Miller, Y., and Shachak, A. (2006). Structured vs. unstructured tagging: A case study. Paper presented at WWW 2006 Collaborative Web Tagging Workshop, May 22, 2006, Edinburgh, Scotland. Retrieved August 8, 2006, from http://www.rawsugar.com/www2006/taggingworkshopschedule.html.

Bearman, D., and Trant, J. (2005). Social terminology enhancement through vernacular engagement: Exploring collaborative annotation to encourage interaction with museum collections. D-Lib Magazine 11(9). Retrieved November 13, 2005, from www.dlib.org/dlib/september05/bearman/09bearman.html.

Brown, P., Hidderley, G. R., Griffin, H., and Rollason, S. (1996). The democratic indexing of images. The New Review of Hypermedia and Multimedia 2: 107-120.

Chun, S., Cherry, R., Hiwiller, D., Trant, J., and Wyman, B. (2006). Steve.museum: An ongoing experiment in social tagging, folksonomy, and museums. Paper presented at Museums and the Web 2006, March 22-25, 2006, Albuquerque, NM. Retrieved August 16, 2006, from http://www.archimuse.com/mw2006/papers/wyman/wyman.html.

Duhaime, C. P., Joy, A., and Ross, C. A. (1989). A picture speaks a thousand words: The consumption of contemporary art. Montréal, QC: École des hautes études commerciales. 
Dunn, H. (2000). Collection level description: The museum perspective. D-Lib Magazine 6(9). Retrieved July 26, 2001, from http://www.dlib.org/dlib/september00/dunn/09dunn.html

Enser, P. G. B. (1995). Progress in documentation: Pictorial information retrieval. Journal of Documentation 51(2): 126-170.

Eversmann, P. K., Krill, R. T., Michael, E., Twiss-Garrity, B. A., and Beck, T. R. (1997). Material culture as text: Review and reform of the literacy model for interpretation. In A. S. Martin and J. R. Garrison (eds.), American material culture: The shape of the field (pp. 135-167). Winterthur, DE: Henry Francis du Pont Winterthur Museum.

Frost, C. O., Taylor, B., Noakes, A., Markel, S., Torres, D., and Drabenstott, K. M. (2000). Browse and search patterns in a digital image database. Information Retrieval 1: 287-313.

The Getty Center for Education in the Arts and The J. Paul Getty Museum (1991). Insights: Museums, visitors, attitudes, expectations. A focus group experiment. Los Angeles, CA: The Getty Center for Education in the Arts, The J. Paul Getty Museum.

Getty Standards and Digital Resource Management Program, J. Paul Getty Trust. Categories for the Description of Works of Art (CDWA). Available from http://www.getty.edu/research/ conducting_research/standards/cdwa/

Gilchrest, A. (2003). Factors affecting controlled vocabulary usage in art museum information systems. Art Documentation 22(1): 13-20.

Gilliland-Swetland, A., and White, L. (2004). Museum information professionals as providers and users of online resources. Bulletin of the American Society for Information Science and Technology 30(5): 23-26.

Gordon, C. (1996). Patterns of user queries in an ICONCLASS database. Visual Resources 12(2): 177-186.

Hourihane, C. (1996). The Van Eyck Project, information exchange, and European art libraries. VRA Bulletin, 23(2), 57-60. 
Housen, A. (1983). The eye of the beholder: Measuring aesthetic development. Ed.D. dissertation. Harvard University.

Housen, A. (1987). Three methods for understanding museum audiences. Museum Studies Journal 2(4): 41-49.

Institute for Museum and Library Services (1999). The 21 ${ }^{\text {st }}$-century learner: Common understandings and common strategies. Discussion paper from meeting convened by IMLS, Washington, DC, March 22-23, 1999.

Janney, K., and Sledge, J. (1995). A user model for CIMI Z39.50 application profile. Consortium for the Computer Interchange of Museum Information (CIMI). Retrieved July 18, 2005, from http://www.cimi.org/public_docs/Z3950_app_profile_0995.html.

Jörgensen, C. (2003). Image retrieval: Theory and practice. Lanham, MD: The Scarecrow Press.

Leinhardt, G., Tittle, C., and Knutson, K. (2002). Talking to oneself: Diaries of museum visits. In G. Leinhardt, K. Crowley, and K. Knutson (eds.), Learning conversations in museums (pp. 103133). Mahwah, NJ: Lawrence Erlbaum.

Lisus, N. A., and Ericson, R. V. (1999). Authorizing art: The effect of multimedia formats on the museum experience. The Canadian Review of Sociology and Anthropology 36(2): 199-216.

Lockett, C. (1991). Ten years of exhibit evaluation at the Royal Ontario Museum (1980-1990). ILVS Review: A Journal of Visitor Behavior 2(1): 19-47.

Mann, C. G. (ed.). (1993). The visitor's voice: Visitor studies in the Renaissance-Baroque galleries of the Cleveland Museum of Art 1990-1993. Cleveland, OH: The Cleveland Museum of Art.

Markey, K. (1983). Computer-assisted construction of a thematic catalog of primary and secondary subject matter. Visual Resources 3: 16-49. 
Markey, K. (1986). Subject access to visual resource collections: A model for computer construction of thematic catalogs. New York, NY: Greenwood Press.

McDermott-Lewis, M., et al. (1990). The Denver Art Museum Interpretive Project. Denver: Denver Art Museum.

McManus, P. M. (1989). Oh, yes, they do: How museum visitors read labels and interact with exhibit texts. Curator 32(3): 174-189.

The Metropolitan Museum of Art (2005). Image cataloguing test. December 7, 2004. Retrieved May 2006, from http://www.steve.museum/reference/MMAImageCatalogingTest12-7-04.pdf.

Panofsky, E. (1955). Iconography and iconology: An introduction to the study of Renaissance art. In Erwin Panofsky, Meaning in the visual arts (pp. 26-54). New York, NY: Doubleday Anchor.

Seren, T., Donohue, D., and Underwood, L. A. (2001). Integrated art documentation: The Guggenheim perspective. Art Documentation 20(1): 31-35.

Shatford, S. (1986). Analyzing the subject of a picture: A theoretical approach. Cataloging \& Classification Quarterly 6(3): 39-62.

Smith, M. K. (2006). Art information use and needs of non-specialists: Evidence in art museum visitor studies. $\mathrm{PhD}$ dissertation. University of Washington.

Smithsonian Institution, Office of Policy and Analysis (2004). The return of the Buddha: Two studies of visitor responses to the exhibition. Retrieved January, 2006, from http://www.si.edu/opanda/Reports.htm.

Smithsonian Institution, Office of Policy and Analysis (2005). Asia in America: Views of Chinese art from the Indianapolis Museum of Art. Two studies of visitor responses to the exhibition. Retrieved January, 2006, from http://www.si.edu/opanda/Reports.htm. 
Stainton, C. (2002). Voices and images: Making connections between identity and art. In G.

Leinhardt, K. Crowley, and K. Knutson (eds.), Learning conversations in museums (pp. 213-257). Mahwah, NJ: Lawrence Erlbaum.

Trant, J. (2006). Exploring the potential for social tagging and folksonomy in art museums: Proof of concept. New Review of Hypermedia and Multimedia 12(1): 83-105.

Trant, J., and Wyman, B. (2006). Investigating social tagging and folksonomy in art museums with steve.museum. Paper presented at WWW 2006 Collaborative Web Tagging Workshop, 22 May 2006, Edinburgh, Scotland. Retrieved May 30, 2006, from www.rawsugar.com/www2006/ taggingworkshopschedule.html.

White, L. (2002). Interpretation and representation: The who, why, what, and how of subject access in museums. Art Documentation 21(1): 21-22.

Worts, D. (1995). Extending the frame: Forging a new partnership with the public. In S. Pearce (ed.), Art in museums (pp. 164-191). New Research in Museum Studies No. 5. London: Athlone.

Zorich, D. (1997). Beyond bitslag: Integrating museum resources on the Internet. In K. JonesGarmil (ed.), The wired museum: Emerging technology and changing paradigms (pp. 171-201). Washington, DC: American Association of Museums. 